\title{
The effect of the depth and groundwater on the formation of sinkholes or ground subsidence associated with abandoned room and pillar lignite mines under static and dynamic conditions
}

\author{
Ö. Aydan $^{1}$ and T. Ito ${ }^{2}$ \\ ${ }^{1}$ Department of Civil Engineering and Architecture, University of the Ryukyus, Nishihara, Japan \\ ${ }^{2}$ Toyota National College of Technology, Toyota, Aichi, Japan \\ Correspondence to: Ö. Aydan (aydan@tec.u-ryukyu.ac.jp) \\ Published: 12 November 2015
}

\begin{abstract}
It is well known that some sinkholes or subsidence take place from time to time in the areas where abandoned room and pillar type mines exist. The author has been involved with the stability of abandoned mines beneath urbanized residential areas in Tokai region and there is a great concern about the stability of these abandoned mines during large earthquakes as well as in the long term. The 2003 Miyagi Hokubu and 2011 Great East Japan earthquakes caused great damage to abandoned mines and resulted in many collapses. The author presents the effect of the depth and groundwater on the formation of sinkholes or ground subsidence associated with abandoned room and pillar lignite mines under static and dynamic conditions and discusses the implications on the areas above abandoned lignite mines in this paper.
\end{abstract}

\section{Introduction}

Some caving, collapses and subsidence take place from time to time in the areas where abandoned room and pillar type mines exist. If the area is urbanized, it presents a great concern to the municipalities as well as to the people living in those areas. Furthermore, if the seismicity of areas is high, the risk of collapses due to earthquakes may amplify those concerns. The 2003 Miyagi Hokubu and the 2011 Great East Japan earthquakes clearly indicated that such areas may experience roof collapses and subsidence as well as the ejection of underground waters from the mines (Aydan and Kawamoto, 2004; Aydan and Tano, 2012). The author has been involved with the stability problems of some room and pillar abandoned mines in Tokai Region of Japan and he has been investigating their performance and responses in the long term as well as during earthquakes.

The backfilling of the abandoned lignite mines of room and pillar type is considered and implemented as a countermeasure against the formation of sinkholes or surface subsidence. The major issue is the depth of the abandoned lig- nite mines for the implementation of backfilling. When abandoned mines are deep, the surface effects of failed abandoned mines may be quite small due to bulking of the failed overburden rock. It is also claimed that if the mines are submerged in groundwater, the degradation of surrounding rock becomes negligible and there is no necessity of backfilling. Although such a claim may be true under static conditions, the model tests and observations show that the formation of sinkholes or surface ground subsidence may occur in the areas of abandoned room and pillar lignite mines due to earthquakes (Aydan and Kawamoto, 2004; Aydan and Tano, 2012).

The author is concerned with the depth and ground water on the formation of sinkholes or ground subsidence in the areas of abandoned lignite mines under static and dynamic conditions in this paper. The possible causes of sinkhole formation or ground subsidence under static and dynamic conditions in the areas of abandoned lignite mines have been summarized. Some case history data from Japan and have been compiled and presented as empirical guidelines for the risk assessment of abandoned lignite mines with respect to 

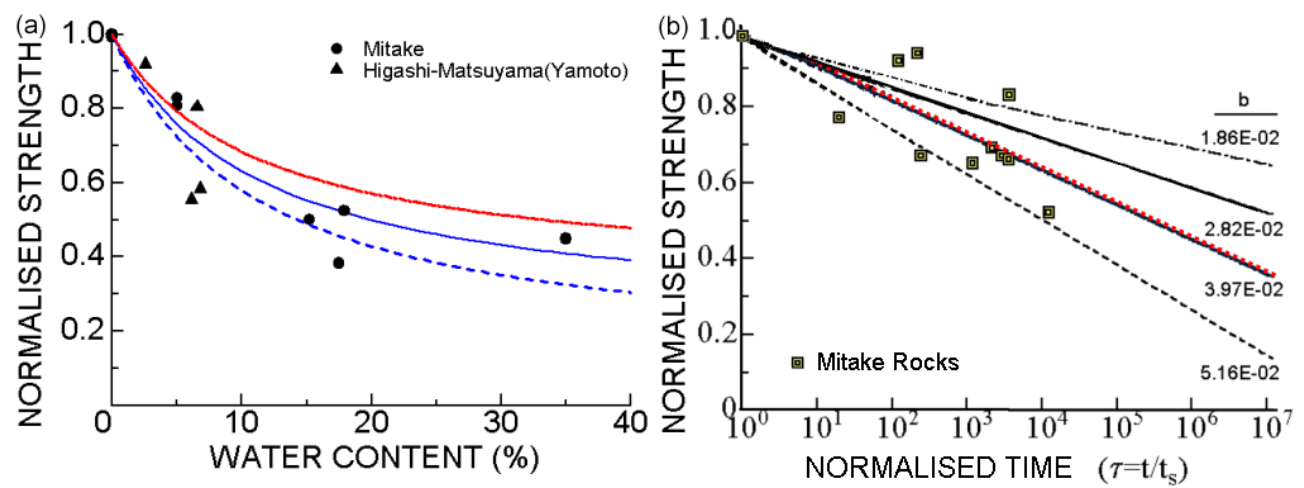

Figure 1. Degradation of strength of rocks of abandoned mines in Mitake with water content and long-term creep loading ( $b$ is empirical coefficient in the empirical long-term strength relation). (a) Effect of water content. (b) Long-term strength.
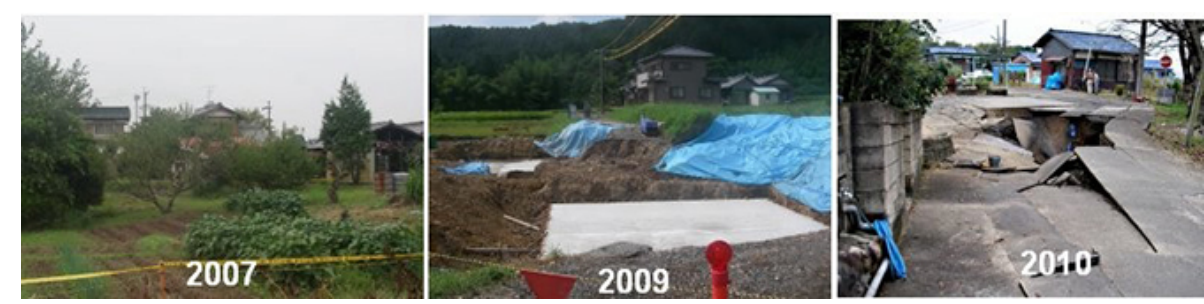

Figure 2. Large sinkholes occurred recently over the abandoned lignite mine in Mitake town.

sinkholes or surface ground subsidence. Furthermore, some suggestions on the quality of backfilling are presented and discussed.

\section{Degradation characteristics of surrounding rocks}

The surrounding rocks and lignite itself in abandoned lignite mines are sedimentary rocks and very prone to degradation due to cyclic variations of water content during absorption and desorption. Such variations cause flaking of surrounding rocks from roof and pillars of lignite seam and results in the reduction of the support area of pillars and thinning of roof layers. Furthermore, the increase of water content results in the reduction of the compressive strength and elastic modulus of soft ocks surrounding (Fig. 1a).

The pillars are subjected to sustained load due to overburden so that the creep phenomenon of surrounding rocks (Fig. 1b) and lignite seam is another cause of the formation of sinkholes or surface subsidence. When the lignite mines are abandoned, they may become wholly or partially submerged in groundwater. The authors experimentally showed that the long-term strength of lignite and surrounding soft rocks drastically reduce upon submergence in groundwater.

\section{Case history data on room and pillar mines}

New constructions over the abandoned mines and earthquakes from time to time cause additional static and dynamic forces on the rock masses of pillars and roofs. As a result of these actions, partial collapses of roof layers, the crosssectional decrease of supporting pillars and even the failure of pillars occurs eventhough their effects may not be observed on the ground surface (Aydan and Tano, 2012). There are some occurrences of sinkholes and large ground subsidence from time to time in Mitake town (Fig. 2).

The authors compiled various data on the formation of sinkholes and subsidence over abandoned mines reported in literature. Sinkholes are generally caused by the degradation of roof layers under different environmental conditions, groundwater flow and vibration effects. On the other hand, subsidence involves failure of rock pillars, and overburden depth and degradation of rock materials are critical parameters. Figure 3a shows the case history data plotted in the space of overburden $(H)$ and settlement $(S)$ normalized by the seam extraction height $(h)$. The majoriy of sinkholes are observed when the overburden is less than 10-15 times the seam extraction height. This implies that the overburden would be $20-30 \mathrm{~m}$ for a seam extraction height of $2 \mathrm{~m}$. However, subsidence may occur at any depth, provided that pillars fail and may initiate after longer time following the termination of mining. There are some examples of delayed failures after about $40-130$ years.

Aydan and Tano (2012) reported some examples of the damage to abandoned mines in Tokai and Tohoku regions by several earthquakes with a moment magnitude greater than 6 . Figure $3 \mathrm{~b}$ shows the relation between the moment mag- 

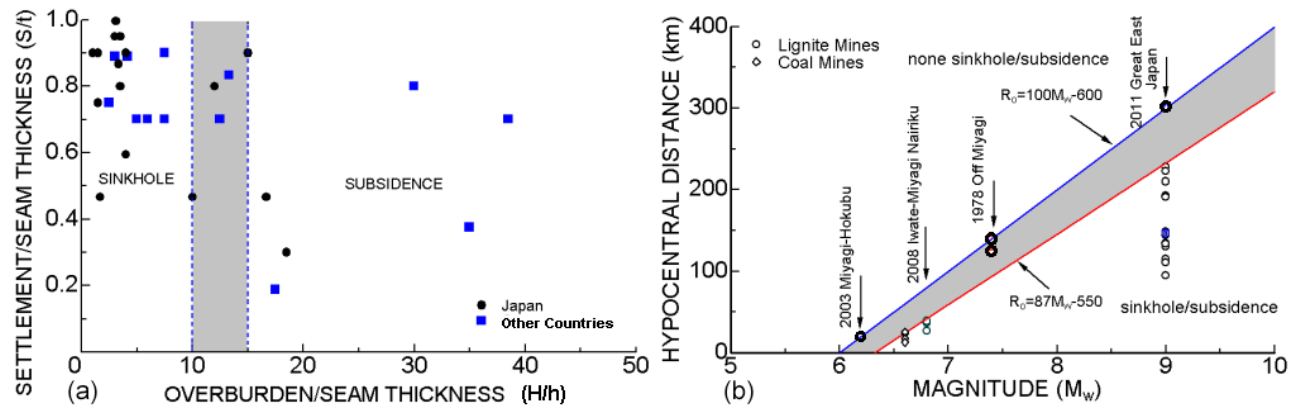

Figure 3. (a) Normalized seam height versus normalized settlement; (b) moment magnitude of earthquakes versus the hypocentral distance of sinkhole/subsidence localities.
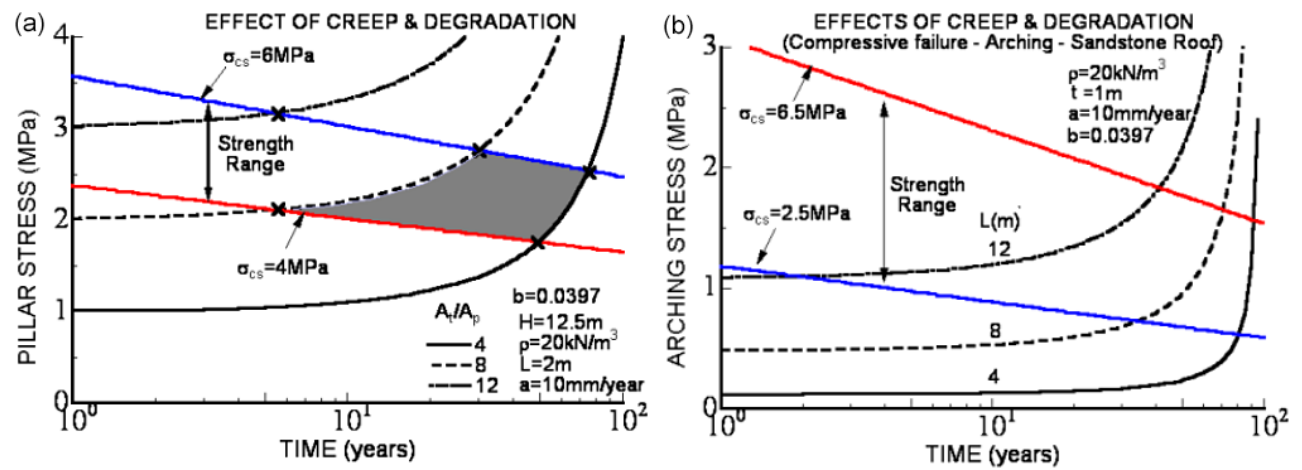

Figure 4. Effects of degradation and creep loading on failure time of pillars and roofs $\left(\sigma_{\mathrm{cs}}\right.$ : short-term uniaxial compression strength; $\rho$ : unit weight of surrounding rock; $A_{\mathrm{t}}$ : supported area; $A_{\mathrm{p}}$; pillar height; $L$ : room width; $a$ : empirical coefficient of degradation function; $b$ : empirical coefficient of long-term strength function, see Aydan et al., 2006 for details). (a) Pillar. (b) Roof consisting sandstone.

nitude of the earthquake and hypocentral distances of sinkholes/subsidence localities. It is of great interest that an envelope defined by linear relations can be inferred between damaged and undamaged regions of the moment magnitude versus hypocentral distance reation. Figure 3 may serve as a guideline to assess the risk of sinkhole or large subsidence due to abandoned mines and quarries exploited using the room and pillar method as a function of earthquake magnitude. However, there is still a great necessity to compile more data to confirm the validity of the proposed relation. Besides the possibility of caving of abandoned mines during earthquakes due to either pillar failure and/or roof failure, the groundwater in mines may present additional effects on the susceptibility pf submerged abandoned mines. These effects may be observed as sloshing, which may further weaken the surrounding rockmass and cause additional collapses.

\section{Considerations on sinkhole formation and ground subsidence}

\subsection{Static condition}

The pillar failure would fundamentally induce ground subsidence while the failure of roof may induce either sinkholes or subsidence depending upon the depth of lignite seam. The tributary area method is simple yet effective method to assess the overall stability of the pillars. Aydan et al. (2006) proposed a procedure for evaluating the stability of pillars subjected to the effect of degradation of lignite under the cyclic wetting and drying and the creep loading. Figure 4a shows both effects of long-term strength and degradation rate. Compared with the failure time of pillar under the condition of creep loading only, the failure time of pillars become shorter. The shaded region (Fig. 4a) corresponds to the estimated conditions of the abandoned mine that the authors have been investigating in Mitake area (Aydan et al., 2006). For the lower bound strength range, the stability problems of pillars would occur after 5.6-50 years and after 30-75 years for the upper bound strength range.

The stability of roof layers can be checked against various forms of failure. Although roof layers may crack due to bending stresses, their ultimate failure would be governed by arching phenomenon (although shear failure may be conceived, it is not generally likely to occur) within the roof layers. If the fiber stress exceeds the compressive strength at the crest of the arch within the roof layer, the roof layer will collapse. The effect of degradation can be imposed on the thickness of roof layer while the effect of long-term strength can be imposed on the compressive strength of roof layers. 

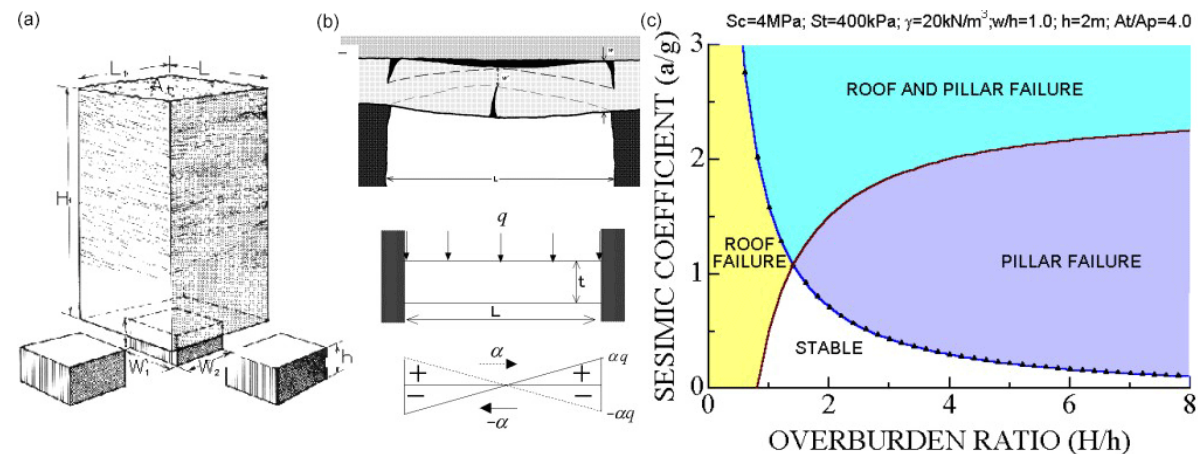

Figure 5. Mathematical model and example of computation for the stability of pillars and roof layers under dynamic conditions. See Aydan et al. (2006) for details. (a) Pillar. (b) Roof. (c) Example of computation.

Figure $4 \mathrm{~b}$ shows some computational results for the effect of creep loading and degradation for sandstone roof.

Groundwater in abandoned mines can be considered to be preventing the degradation of pillars and roof layers. Furthermore, the effective vertical stress acting on the pillar would decrease due to the fluid pressure support provided by groundwater and pillar stress would be given as

$\sigma_{\mathrm{p}}{ }^{\prime}=\frac{1}{1-e}\left(\gamma_{\mathrm{r}} H-\gamma_{\mathrm{w}} H_{\mathrm{w}}\right)$,

where $\gamma_{\mathrm{r}}, \gamma_{\mathrm{w}}, H, H_{\mathrm{w}}$ and $e$ are unit weight of rock, water, overburden, water depth and excavation ratio, respectively. If abandoned mine is fully submerged and water height is equivalent to overburden height, the effective stress acting on the pillar would be decreased by about $43 \%$. However, as noted from Fig. 1a, the strength of the surrounding lignite layer decreases about $60-75 \%$ under fully saturated conditions. In other words, groundwater would further decrease the overall stability of abandoned lignite mines.

\subsection{Dynamic condition}

Aydan et al. (2006) proposed a practical method for evaluating the stability of pillars and roof of abandoned room and pillar lignite mines using the seismic coefficient approach. Figure $5 \mathrm{a}$ and $\mathrm{b}$ show the assumed models for the dynamic stability of pillars and roofs. In this approach, the pillar was assumed to fail under the maximum compressive stress. The load condition under horizontal shaking is assumed to consist of gravitational load inducing the bending stresses and linearly varying axial stress along the roof axis from tension to compression due to horizontal shaking. On the basis of this assumption, the seismic coefficient at the time of roof layer failure by bending is obtained. Figure 5 shows computed diagrams for the relation between overburden ratio and seismic coefficient for various failure modes for the chosen parameters shown in the same figure. These results indicate that the shallow mines are prone to roof failure while the deeper mines are prone to pillar failure for actual strong ground motions during earthquakes.

\section{Conclusions}

The authors considered the effect of the depth and groundwater on the formation of sinkholes and ground subsidence associated with abandoned lignite mines on under static and dynamic conditions and presented some case history data under both static and dynamic conditions. It is shown that sinkhole formation or subsidence of abandoned room and pillar mines, which may take some time, can definitely occur. While sinkhole formation is generally limited to depths 10-15 times the extracted seam height, subsidence can occur over abandoned mines of any depth provided that the pillars fail under both static and dynamic conditions. While the groundwater decreases vertical stress acting on the pillars under fully submerged conditions, the overall stability of the abandoned room and pillar mines would be decreased due to the reduction of strength of the lignite seam and surrounding rocks under saturated condition.

Acknowledgements. The authors sincerely acknowledge the advices on this study by Emeritus Professor Toshikazu Kawamoto of Nagoya University.

\section{References}

Aydan, Ö. and Kawamoto, T.: The damage to abandoned lignite mines caused by the 2003 Miyagi-Hokubu earthquake and some considerations on its causes, 3rd Asian Rock Mechanics Symposium, 30 November-2 December 2004, Kyoto, 525-530, 2004.

Aydan, Ö. and Tano, H.: The damage to abandoned mines and quarries by the Great East Japan Earthquake on March 11, 2011, in: Proceedings of the International Symposium on Engineering Lessons Learned from the 2011 Great East Japan Earthquake, 1-4 March 2012, Tokyo, Japan, 981-992, 2012.

Aydan, Ö., Daido, M., Ito, T., Tano, H., and Kawamoto, T.: Instability of abandoned lignite mines and the assessment of their stability in long term and during earthquakes, 4th Asian Rock Mechanics Symposium, Singapore, Paper No. A0355 (on CD), 2006. 